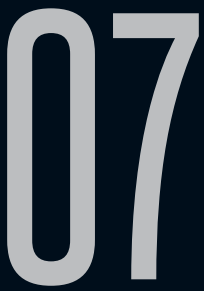

\title{
O APOCALIPSE APÓCRIFO DE JOCA REINERS TERRON EM NÃO HÁ NADA LÁ
}

Elenara Walter Quinhones (UFSM)

Recebido em 23 mai 2018. Elenara Walter Quinhones é Mestra em Letras Aprovado em 25 jul 2018. Literatura, pela UFSM, atualmente Doutoranda em Letras - Literatura, pela UFSM, atua como docente na rede municipal de ensino de Esteio - RS. CV_Lattes: http://lattes.cnpq.br/5135076289658171 E-mail: elenarawalter@gmail.com

Resumo: Este artigo tem como objetivo discutir sobre a metaliteratura encontrada na obra ficcional de Joca Reiners Terron, Não há nada lá (2001). A literatura será a protagonista do romance de Terron; sua importância é tamanha que a inexistência dela causaria o fim do mundo. O autor cria uma analogia entre o fim da literatura e o fim do mundo a partir do livro bíblico do Apocalipse, pautando-se na intertextualidade.

Esse fim da literatura já foi anunciado por muitos especialistas da área, e pode ser entendido como o fim da literatura concebida na modernidade. Seria o final do romance tradicional com uma sequência linear bem conhecida com: início, meio e fim, pertencente a um gênero apenas. Terron preconiza esse término utilizando um romance inovador estruturalmente, com

1 Este artigo foi desenvolvido a partir de um ensaio crítico, apresentado na disciplina de Aspectos da Literatura Contemporânea, ministrada pela Profạ. Drạ Renata de Fellipe, no curso de Doutorado em Letras do Programa de Pós-Graduação em Letras da Universidade Federal de Santa Maria, no primeiro semestre de 2016, entretanto a submissão para publicação é inédita. 
fortes características do gênero fantástico, mas sem abrir mão de uma multiplicidade de outros gêneros encaixados ao longo da narrativa. Essa condição faz com que muitos especialistas considerem o romance como gênero híbrido, porém nós escolhemos analisálo como fantástico contemporâneo. Para sistematizar esta discussão, a dividimos em três tópicos: a primeira, que tratará da metaliteratura, pautada nas concepções de Hélder Gomes (2010), Leyla Perrone-Moisés (2011) e Linda Hutcheon (1980; 1988). A segunda abordará a autoconsciência autoral. Para essa abordagem, utilizamos como aporte teórico Karl Schollhammer (2011) e Beatriz Resende (2008). Quanto ao gênero, ressaltamos o viés do fantástico contemporâneo e para isso nos pautamos nas concepções de Jean-Paul Sartre (1968). Por fim, será tratado do apocalipse apócrifo criado por Terron, com base nos conceitos de intertextualidade de Kristeva (1969).

Palavras-chave: Não há nada lá; Metaliteratura; Joca Reiners Terron.

Abstract: This article aims to discuss the metaliterature found in the fictional work by Joca Reiners Terron, Não há nada lá (2001). Literature is the main character of Terron's novel, it's so important that the inexistence of it may have caused the end of the world. The author creates an analogy between the end of literature and the end of the world from the biblical book of Revelation, based on intertextuality. The literature's end has already been announced by many experts in the field and can be understood as the end of literature conceived in modernity. It would be the end of the traditional novel with a wellknown linear sequence: beginning, middle and end, belonging to a single genre. Terron advocates this term using a structurally innovative novel, with strong characteristics of the fantastic genre, but without giving up a multiplicity of other genres embedded throughout the narrative. This condition causes many 
experts to consider romance as a hybrid genre, but we choose to analyze it as a fantastic contemporary. To systematize this discussion, we split it into three topics: the first one, which deals with metaliterature, based on the conceptions by Hélder Gomes (2010), Leyla Perrone-Moisés (2011) and Linda Hutcheon $(1980,1988)$. The second one will deal with the authorial self-consciousness. For this approach, we use as theoretical contribution Karl Schollhammer (2011) and Beatriz Resende (2008). As for the genre, we emphasize the bias of the fantastic contemporary and for this we are guided by the conceptions by JeanPaul Sartre (1968). Finally, it will be treated of the apocryphal apocalypse created by Terron, based on the concepts of intertextuality by Kristeva (1969).

Keywords: Não há nada lá; Metaliterature; Joca Reiners Terron.

\section{INTRODUÇÃO}

Durante um longo período da história literária, os romances seguiram uma lógica linear: com começo, meio e fim. Os enredos seguiam uma estrutura mais ou menos complexa, que envolviam acontecimentos da vida e do cotidiano dos protagonistas e o enlace com outras personagens secundárias. Os conflitos com antagonistas, geralmente, eram o clímax do romance, e, em sua maioria, o desfecho era bem amarrado. Algumas tramas mostravamse com conteúdo histórico, outras mais políticas, mas em termos de estruturas não se modificavam das demais.

Na modernidade, o fluxo de consciência tomou grande parte das narrações. Os fatos já não eram apenas narrados, mas elaborados a partir de uma ótica introspectiva e complexa seguindo a lógica do pensamento humano. A linearidade oscilou, os objetos e o mundo 
perderam o valor para serem mimetizados. O pós-guerra teve uma repercussão na forma de criar a arte literária, afinal, diante do horror da guerra, o sujeito não era o mesmo e seu jeito de contar histórias também não.

Dessa forma, a literatura vem se modificando até a contemporaneidade. Muitas mudanças são observadas a partir das décadas finais do século XX. Nesse sentido, o romance Não há nada lá, de Joca Reiners Terron, serve como modelo vivo para a literatura contemporânea, cuja fragmentação e intertextualidade são expostas de uma forma complexa e diferente. Este artigo tem o objetivo de expor essas mudanças refletindo sobre o intrincado jogo construído por Terron.

Em um primeiro momento pensaremos na protagonista da história - a própria literatura. Logo em seguida, analisaremos as questões autorais dentro da lógica contemporânea. Por fim, verificaremos a análise do romance análogo ao livro apocalíptico da Bíblia Sagrada. O inusitado paralelo aguça nossa curiosidade e faz com que pensemos a obra também de uma forma inusual tratando-a como um livro apócrifo criado por Terron.

\section{A LITERATURA PÓS-REALISMO FORMAL: METALITERATURA}

No final da década de 1970, apresentou-se uma nova forma de compreender e teorizar alguns textos literários que se desvinculam da noção de romance realista do século XIX. Segundo Hélder Gomes (2010), foi nesse período que William Gass denominou esses textos de metaficções ${ }^{2}$, em que o conceito de metaliteratura estaria

2 Algumas correntes teóricas utilizam os termos metaficção e metaliteratura como sinônimos, outras os diferenciam. Para fins deste artigo, optei por colocá-los como sinonímia, privilegiando o termo metaliteratura coerente ao conceito utilizado por 
inserido. Gass (1974) criou o termo metaficção para aplicá-lo aos textos que a crítica norte-americana chamava de antirromances, por modificarem a forma mimética tradicional.

Conforme Gomes (2010), essa literatura terá como características fundamentais a desdogmatização, a desconstrução, a sátira, a paródia dos limites sociais, estéticos e artísticos. Em consonância com Ian Watt (1990), estudioso do romance realista formal, a literatura realista procurava apresentar a veracidade dos fatos, aproximando a vida da arte literária. Já na metaliteratura acontece uma reescrita da realidade através da literatura, "e uma denúncia ao artifício e à tentativa de fabricar realidades quase laboratoriais, que de reais quase nada tinham" (GOMES, 2010, online).

A metaliteratura (ou metaficção) estaria atrelada também à própria mudança na concepção de sujeito social. Conforme Stuart Hall (2010), na pós-modernidade acontecerá o que se denomina de a crise do sujeito, quando se perde a noção de identidade, como unidade centrada e invariável, para tornar-se um sujeito cuja identidade é fragmentária e contraditória.

Da mesma forma, na literatura muda-se a concepção do narrador clássico. Não há mais uma preocupação em narrar a vida humana, o cotidiano, mas a produção literária em si. Podese dizer, então, que metaliteratura seria uma literatura que se autorreferencia. Ela caracteriza-se por uma autoconsciência tanto no que diz respeito ao texto propriamente dito, como na forma em que ocorre a construção linguística, que geralmente manifesta-se como narrativa de encaixe (mise en abyme).

Leyla Perrone-Moisés. Para autora, metaliteratura se refere ao tipo de literatura contemporânea em que se misturam diversos gêneros, incluindo a própria crítica literária (PERRONE-MOISÉS, 2011, online). 
Diferente da narração inscrita no romance realista, em que é importante disfarçar o processo envolvido na criação do texto e na própria linguagem, para acentuar a impressão de realidade, a metaliteratura deixa visível o processo de concepção do texto, expõe, por vezes, até uma autocrítica. Além disso, ela se utiliza de outros processos de representações os relacionando, o que resulta em um profundo grau de intertextualidade com outros textos literários ou com outras manifestações artísticas como cinema, música, teatro, etc.

Linda Hutcheon em seu livro Narcissistic narrative: the metafictional paradox (1980), demonstra como a narrativa metaficcional expande o conceito inicial de mimesis, como apenas imitação através da história contada, para um conceito que abrange a como essa história é contada. Já no seu livro Poetics of postmodernism (1988), Hutcheon aborda o conceito de metaficção sempre pelo viés político. Ela menciona que, ao tratar-se de metaficção historiográfica, os paradoxos entre ficção e história, particular e geral, presente e passado, o eu e o outro parecem confrontar-se, porém não há como escolher qualquer parte dessa dicotomia.

Embora já houvesse textos metaficcionais no passado, a metaliteratura se desenvolve especialmente após a Segunda Guerra Mundial, quando ganhou um estatuto existencialista, conforme Hutcheon (1980). A desconstrução dos paradigmas da modernidade, ocasionado pelo pós-guerra teve reflexo expressivo na arte de narrar, que se afastou profundamente das formas tradicionais do realismo. Acentua-se, assim, uma literatura de caráter autorreflexivo e autoconsciente. 
A autorreflexividade na metaliteratura, conforme Hélder Gomes (2010), se encontra na reflexão de sua própria condição ao parodiar ou criticar qualquer dogma existente no entorno textual (inter e intra-textual). Gomes comenta que a metaliteratura é

o espaço do outro, do marginal, daquele que não teve lugar como herói numa literatura dogmatizada e ao serviço de uma ordem social cheia de pre(-) conceitos. São desta feita chamados para contar a sua história gays, lésbicas, loucos, mulheres, nativos e até pequenos vermes. (2010, online, grifo do autor)

Quanto à autoconsciência, trata-se de consciência do autor e do texto, no que se refere a sua própria identidade ficcional, exposta de forma incisiva.

Finalmente, pode haver na metaliteratura uma mescla de gêneros literários, uma polifonia de vozes e múltiplas perspectivas narrativas. Como explicado por Gomes, ela

[expande] os limites da sua gênese através, entre outras, de técnicas narrativas que contemplam a intromissão autoral, estruturas narrativas não lineares no que concerne ao espaço, tempo e discurso, pastiche e paródia intertextual, não só pela estilização crítica de textos pertencentes ao mesmo género literário, como também de textos inscritos noutros géneros literários, e até textos que normalmente nem sequer são tidos como literatura, como é o caso dos documentos históricos. (2010, online)

Notoriamente, a literatura atual constitui-se muitas vezes de hibridismos em sua estrutura, no caso de Não há nada lá, isso também acontece. Há no romance uma mistura de linguagens que 
variam do coloquial até a norma-padrão, de gêneros textuais, como cartas, discursos e profecias. Porém, do ponto de vista de gênero literário há a predominância do fantástico. Para Sartre (1968), o fantástico contemporâneo difere-se do fantástico exposto por Todorov, ele será a forma que os autores utilizam para mostrar a realidade através do absurdo. Vejamos como isso se desenvolve dentro desse texto metaliterário criado por Terron.

\section{AUTOCONSCIÊNCIA AUTORAL DE JOCA REINERS TERRON EM NÃO HÁ NADA LÁ}

Conforme exposto até aqui, a metaliteratura, por uma multiplicidade de fatores, rompe com as estruturas dos romances realistas. Ela apresenta uma nova forma de narrar, em que a autorreflexividade e a autoconsciência são elementos fundamentais. A autorreflexividade pode ser entendida de duas formas: no sentido exposto por Hélder Gomes (2010), de reflexão (pensar) sobre si mesma; ou no sentido de refletir a si de forma especular, autoespelhamento, verificável na estrutura de mise in abyme. Neste tópico, adentraremos a autoconsciência, no que concerne ao processo autoral, especificamente no romance Não há nada lá (2001), de Joca Reiners Terron.

Na metaliteratura se perde a pretensão de descrever o mundo, o que toma lugar de destaque nessas narrativas é tudo o que envolve o processo criativo em si. No caso do romance Não há nada lá, o que ganhará ênfase é a própria literatura. Segundo Schollhammer (2011), Terron não se distancia da literatura, ele "convive com os escritores [, com as] suas vidas e obras, cria enredos que nos introduzem em segredos por trás da criação, converte os personagens literários em 
personagens de outros dramas, sem escrever biografias ou propor explicações ao sentido das ficções" (p.131). Conforme Cristovão Tezza (2002, online), "a narração de Não há nada lá é um canto de paixão à literatura".

O autor de Não há nada lá subverte a narrativa realista, tanto temporal, como espacialmente. Segundo Beatriz Resende (2008), comentando a respeito das obras de Terron, mais especificamente Curva de rio sujo, porém aplica-se também a Não há nada lá,

[e]m seu último livro, permanece uma espécie de desfazimento do espaço, mas predomina uma certa trip atemporal, um atravessar tempos de outros gostos e outras escritas, de repertórios diversos criados em espaços e tempos inacabados ou, ostensivamente, deslocados. (RESENDE, 2008, p.132).

Não há uma sequência linear na capitulação do romance, ele começa no capítulo 48 (quarenta e oito) decrescendo até o 0 (zero) e termina com uma espécie de índice enciclopédico sobre as personagens, acrescido ao livro publicado em 2001.

Quanto ao tempo da narrativa, não há uma linearidade cronológica como nas narrativas mais tradicionais, traço bastante comum na literatura contemporânea. Há uma união temporal entre as diversas personagens através da aparição do Tesseract, um hipercubo que aparece de forma fantástica já no primeiro capítulo. Cristovão Tezza (2002) fornece um pequeno resumo do encontro dessas personagens, como uma espécie de mosaico montado por Terron: 
- livro mágico como referência, Terron promove o encontro de Papa Pio XI com Raimundo Roussel em 1926, faz Torquato Neto conversar com Jaime Hendrix em 1970, flagra Ducasse no compartimento de um trem em 1867 furtando um exemplar de As flores do mal, "com um brilho fantasmagórico na capa", de um "pederasta ancião", assiste ao encontro de Rimbaud com o xerife Patrício Garret em 1881, vê Alistério Crowley se aproximando de Fernando Pessoa em 1930 e daí por diante. (TEZZA, 2002, online)

Em um primeiro olhar, parece-nos que Não há nada lá é criado a partir da simples sobreposição de pequenos relatos que não tem muita coerência nem unicidade, porém essa fragmentação é profundamente aparente.

Embora os capítulos possam ser lidos quase aleatoriamente, há uma sequência exata de capítulos e de personagens que terão como pano de fundo uma "mitologia maldita da literatura" (SCHOLLHAMMER, 2011, p.132). Nesse sentido, podemos afirmar que quanto mais autoconsciente o autor se torna, mais ocorrerão transformações na sua forma de criar. Coerente com o que expõe Schollhammer (2011), "Joca Reiners Terron rompe com todas as tendências tradicionais da literatura brasileira, escreve no campo minado entre ensaio e ficção, usando entrevistas, diários, anotações e fragmentos, sem abrir mão da liberdade imaginária e do atrevimento transgressivo na realização" (p.134). O romance de Terron não apresenta apenas um descompasso com a narrativa tradicional na temporalidade, na espacialidade, e na estrutura composicional, mas também na mistura de múltiplos gêneros e na utilização de imagens, o que não deixa de apresentar o traço ligado com sua biografia como artista gráfico. 
O fantástico é habitado por seres humanos e naturais, no entanto, o homem é apresentado às avessas, o que exporia a condição humana. Porém, essa condição humana não é adentrada pelo o uso de ideias morais ou filosóficas ao longo das narrativas, mas pela condição implícita do próprio absurdo inerente aos fatos humanos. Em Não há nada lá temos o fim do mundo ou o fim da literatura, ambos convergindo de ações humanas cotidianas. No romance não há a hesitação do leitor ante ao elemento fantástico, mas um estranhamento desses elementos, por esse motivo o fantástico pensado por Todorov (2006) não se adequa ao romance de Terron. Outra definição do fantástico contemporâneo, diferente do exposto por de Todorov, é que não há uma acentuação da ambiguidade. Entidades mágicas não são mais necessárias nesse tipo de fantástico, fadas, duendes, gênios, seriam convenções inúteis e velhas.

Mas por qual motivo Terron recorreria ao fantástico em sua obra? Talvez Borges possa nos responder essa questão, para o autor o fantástico não seria uma fuga da realidade, mas sim a expressão de uma outra visão de realidade que não a trivial. Como falar do fim do mundo sem parecer profeticamente religioso? Como decretar o fim da literatura em meio aos teóricos literários tão fechados em sua redoma de Letras? Como comparar o fim do mundo com o fim da literatura? Terron responde a todas essas dúvidas em seu romance. Ele vê a realidade de uma forma diferenciada, decreta o fim de sua matéria-prima de forma profeticamente escondida sob a capa da literatura fantástica.

De acordo com Beatriz Resende (2008), o que faz com que Joca Terron crie uma literatura tão bem trabalhada, tendo como temática 
central a própria literatura, não se deve apenas a sua erudição, ou a sua intertextualidade com outras mídias e seu conhecimento de crítica literária em geral, mas deve-se ao fato dele conseguir percorrer um caminho do meio entre o repúdio à cultura de massa e o hermetismo erudito do moderno. $\mathrm{O}$ autor parece se apropriar de ambos, sem, no entanto, deixar de ter uma forma única de compor seu texto.

Não há nada lá apresenta uma profunda ligação com os poetas malditos a partir de Baudelaire, do decadente Rimbaud, sem excluir a cultura pop com a figura de Jimi Hendrix, acrescido da mitologia cristã com as personagens Papa Pio XI e a pastorinha Lúcia. Todos esses elementos são misturados, de forma a parecer aleatória, mas que na verdade terão como fio condutor a profecia de Apocalipse (livro atribuído ao profeta cristão João, pertencente ao Novo Testamento) sobre o fim do mundo, vejamos de que forma isso acontece.

\section{O APOCALIPSE APÓCRIFO EM NÃO HÁ NADA LÁ}

Não há nada lá inicia com uma de suas personagens, Guilherme Burgos, escritor aposentado, sentado em sua casa, refletindo sobre o livro que tem em mãos, ele afirma: "Não me parece restar tempo para você neste mundo, meu velho. A perfeição simplesmente, de uma hora para outra, deixou de existir para nós. Pergunto-me como seria a morte do livro. Diga, como morrem os objetos perfeitos?" (TERRON, 2011, p.153). Logo em seguida, o escritor joga o livro para o céu, comparando-o com um pássaro, esse voo é suspenso pela aparição fantástica do hipercubo, que o faz permanecer suspenso no ar e depois desaparecer.

Assim começa o jogo de Terron. A história de Burgos só continuará após seis capítulos. Temos a seguinte sequência: 7 (sete) 
personagens, que ganharão a continuidade de suas histórias de 7 (sete) em 7 (sete) capítulos. Essa reiteração do número 7 (sete) poderia parecer mero acaso, porém o sétimo capítulo (41, quarenta e um) apresentará uma referência bastante significativa para uma das possíveis leituras da obra do autor. Esse capítulo narra o aparecimento do livro jogado por Burgos, que é arremessado novamente em seu quintal, mas com rasuras em suas palavras e selado com 7 (sete) selos.

Na tradição judaico-cristã, encontramos uma menção aos 7 (sete) selos no livro do profeta João, o livro do Apocalipse. Todo o livro narra as visões proféticas do escritor sobre o fim do mundo, a luta final entre o bem e o mal e a situação da humanidade nesse ínterim. Na profecia mística, João vê Deus, que está sentado em um trono celestial, acompanhado por anjos, e em seu entorno há sete candelabros (que representam sete igrejas da Ásia), e os sete espíritos de Deus. Vejamos o que dizem os três primeiros versículos do capítulo 5 (cinco) de Apocalipse:

1) Então vi na mão direita daquele que está assentado no trono um livro em forma de rolo escrito de ambos os lados e selado com sete selos.

2) Vi um anjo poderoso, proclamando em alta voz: "Quem é digno de romper os selos e de abrir o livro?"

3) Mas não havia ninguém, nem no céu nem na terra nem debaixo da terra, que podia abrir o livro, ou sequer olhar para ele. (APOCALIPSE, 5:1-3, online)

Podemos ressaltar dois elementos importantes nesse fragmento bíblico: o fato de estar nas mãos de Deus um livro; e de ninguém 
ser digno o suficiente para abri-lo. Na obra de Terron, Guilherme Burgos abre o livro, rompendo os sete selos, embora inebriado pela presença mística do Tesseract.

Após o capítulo 41 (quarenta e um) há um subcapítulo, sem numeração, intitulado Da consideração, nele há uma explicação superficial do que seria o hipercubo:

O Tesseract é um cubo quadridimensional, também conhecido como hipercubo. [...]

A maioria dos leigos está familiarizada com as três dimensões do espaço (largura, profundidade e altura), mas qual deve ser a quarta dimensão para que um simples cubo se torne hipercubo? Essa dimensão é o tempo. [...]

A principal característica de tal Tesseract seria sua impermanência, pois o cubo viajaria através do espaço e, simultaneamente, viajaria no tempo, existindo, como volume cúbico, apenas durante o tempo necessário para atravessar o espaço. (TERRON, 2011, p.145; 144; 143 - grifo do autor)

Embora a explicação não seja explícita, o Tesseract pode ser entendido como uma espécie de entidade celestial, ou como uma metáfora para uma divindade. A epígrafe que inicia o subcapítulo citado anteriormente é a seguinte frase, de São Bernardo de Claraval: "O que é Deus? É longitude, largura, altura e profundidade" (TERRON, 2011, p.143), todas as dimensões abarcadas pelo hipercubo.

Essa passagem de limite fronteiriço entre o real e o irreal, do cotidiano familiar para o improvável perturbador, que é permitida na literatura fantástica é o que possibilita a inserção desse elemento mágico, o hipercubo, no romance de Terron. 0 leitor acostumado com a literatura moderna terá de reavaliar 
seus conceitos e ver esse texto a partir de uma dimensão longe da costumeira, para orientar-se e compreender o funcionamento dele. Embora não utilizemos as noções formuladas por Todorov, sobre o fantástico, cabe lembrar que o teórico enfatizou que os "distúrbios da personalidade, os jogos do visível e invisível, as alterações de causalidade, do espaço e do tempo; a regressão" são típicos elementos do fantástico (TODOROV, 2006, p.108). A presença o hipercubo mágico está sempre ligada ao tempo. Toda a vez em que ele aparece as barreiras tempo e espaço se desfazem e temos o encontro de personagens do passado e do presente convivendo simultaneamente e interagindo entre si.

O leitor do romance é levado a sair do seu mundo familiar para acreditar em uma quase entidade divina, que influenciaria nas ações das personagens. Porém o narrador não é explícito sobre o quê ou quem é essa divindade. Isso resulta em um efeito de surpresa, de desorientação e de humor no leitor. Trata-se de um sinal de forte empenho cognitivo de Terron em dissimular a seriedade expressa em Apocalipse e mesmo assim manter o tom profético de extermínio que o fim do mundo apregoa.

Ao retornarmos à leitura da profecia sobre os 7 (sete) selos, do Apocalipse (capítulos 6 (seis) e 7 (sete)), vão sendo revelados quem abrirá os selos e o que significa cada um deles. Na profecia bíblica, quem abrirá os selos será o cordeiro, essa metáfora é utilizada para indicar a Jesus Cristo, que se sacrificou pela humanidade, segundo a escatologia cristã. A ele também se refere a expressão "o leão da tribo de Judá", mencionada por um dos anciões que rodeiam o trono celestial. 
Os 4 (quatro) primeiros selos referem-se aos 4 (quatro) cavaleiros do Apocalipse: o cavalo branco cavalgado pelo Anticristo; o cavalo vermelho que simboliza as guerras; o cavalo negro que representa a fome; e o cavalo amarelo que indica as pragas que consumiriam a humanidade decorrentes das guerras e da fome. O quinto selo corresponderia aos que sofreram e morreram pela fé cristã, tornandose mártires. O sexto selo representa os terremotos que aconteceriam nos fins dos tempos, e por fim, quando Cristo rompe o sétimo selo, 7 (sete) anjos tocam 7 (sete) trombetas para anunciar o juízo final.

Mas que associação tem tal profecia apocalíptica com a obra de Joca Reiners Terron? A resposta para essa pergunta encontrase somente no subcapítulo anterior ao último capítulo do livro, intitulado O Bispo de Macau, e no capítulo final (0, zero). Quando um burocrata, Paulo José Tavares, é escolhido para ler a carta deixada por Lúcia, pastorinha que presenciou a aparição da Virgem Maria e após adulta tornou-se freira, na qual estava transcrito o terceiro segredo de Fátima referente à aparição.

O burocrata havia chegado ao bispado por conhecer tal segredo, porém tinha-o abandonado, e agora morava no Brasil com uma mulata, sendo dono de um bar no subúrbio de São Paulo. O bispo, agora alcoolista, narra sobre o terceiro segredo de Nossa Senhora de Fátima, que revelava a aparição do Tesseract e do livro com os 7 (sete) selos que seria devolvido para Guilherme Burgos, cada um dos selos seria rompido pelos escolhidos (escritores e poetas que formam o mosaico de personagens de Não nada lá). Essa carta formaria uma espécie de Apocalipse apócrifo, em que Lúcia seria a responsável pela transcrição profética do final dos tempos, tal como João. Conforme o seguinte excerto: 
Lúcia observa o livro que a Senhora [Nossa Senhora de Fátima] traz fechado nas mãos. Sua capa de couro de carneiro traz sete selos, cada um deles uma diferente imagem. $\mathrm{O}$ primeiro tem um velho [Guilherme Burgos] estirado numa cadeira, no céu sobre sua cabeça há um cubo de luz idêntico ao que envolve a Virgem. No segundo selo, há um senhor [Raimundo Roussel] distintamente vestido ao lado de um estranho carro em forma de caracol, carregando em sua traseira algo semelhante a uma casa, ao fundo há um deslumbrante palácio. No terceiro selo, dois rapazes [Torquato Neto e Jaime Hendrix] de cabelos compridos, um branco e outro negro, e há um raio unindo os punhos que apontam um em direção ao outro. No quarto selo aparece a imagem do outro jovem [Isidore Ducasse] observando o trem distanciar-se, ele está de costas, mas é visível um livro embaixo de seu braço. O quinto selo mostra um moço [Arthur Rimbaud] espadaúdo em mangas de camisa que carrega dois baldes à margem de um riacho, ao longe um círculo de pessoas envolve um homem de revólver na mão com aspecto triunfante. No sexto selo há um imenso despenhadeiro, sobre ele um cavalheiro [Fernando Pessoa] luta contra o vento impiedoso. O sétimo selo reproduz a cela do Convento das Irmãs Dorotianas onde Lúcia se encontra, nele a freira vê-se ajoelhada. Diante dela há um admirável cubo de luz que gira em velocidade alucinante, dentro do cubo há um livro levitando no ar, na capa do livro existem sete selos [...]. (TERRON, 2011, p.16-17)

Após esse excerto a narrativa continua parafraseando o livro bíblico do Apocalipse, porém o fim do mundo de Não há nada lá se diferencia ao do narrado pelo profeta João. O mundo criado por Terron acabaria com a morte do livro, conforme é 
possível averiguarmos nos diversos excertos proféticos inseridos aleatoriamente ao longo da narrativa. Esses relatos aparecem no meio das histórias das personagens, somente identificáveis pela alternância de fonte (itálico) e descontextualização temática: "um viva à literatura, somente a literatura, fundadora da realidade que conhecemos através da linguagem, construtora de mundos, somente a literatura poderia deflagrar o fim de algo que ela mesma erigiu" (TERRON, 2011, p.30 - grifo do autor).

Não há nada lá tem como protagonista a própria literatura, em toda a sua extensão e o seu fim. As personagens ficam em um papel secundário, girando ao redor do eixo centralizador que é a própria literatura. Na obra, o livro toma ares de divindade, de local sagrado em que está inscrito a vida e a morte, a própria entidade que o segura perde seu encanto místico diante do "objeto perfeito" (TERRON, 2011, p.153). O jogo de intertextualidade produzido por Terron, entre o livro bíblico e o apocalipse apócrifo, deixa o leitor perplexo. Ele precisa encontrar respostas, porém fica preso à falta de recursos para buscá-las. Como o romance é fragmentado e não há uma personagem principal como condutora aparente, é natural que haja um estranhamento inicial. Essa condição é bastante comum no fantástico contemporâneo.

O tom satírico e bem humorado das historietas não nos lembra em nada as previsões sombrias do profeta João. A intertextualidade, conforme Julia Kristeva (1969), tem o caráter de desconstruir a subjetividade autoral. No entanto, Terron consegue manter uma marca autoral bastante singular, mesmo utilizando como personagens pessoas reconhecidas. Segundo Schollhammer (2011), "[t]odas as histórias reinventadas da mitologia maldita da 
literatura são costuradas por fenômenos que revelam a potência oculta da literatura de tomar posse da realidade e criar suas redes e estruturas, cuja lógica apresenta temporalidades descontínuas" (p.32). Não há nada lá consegue manter em sua trama a união de universos distintos e distantes temporalmente.

Leyla Perrone-Moisés (2011), aborda o anunciado fim da literatura em um ensaio nomeado "O Longo Adeus à Literatura", na Folha de São Paulo. Esse fim é na realidade o fim da literatura concebida na modernidade. Dessa forma, quebra-se com a sequência tradicional do romance, cujo clímax apresenta o momento de maior aprisionamento do leitor e varia apenas o final que poderá ser, em alguns casos, em aberto. Podemos pensar que seja esse fim que Terron preconiza em Não há nada lá, o fim de um fazer literário de fórmula quase pronta. Para Perrone-Moisés, os leitores não querem mais ler livros que os teóricos do século $X X$ consideravam literatura. Ela mudou, embora se utilize cada vez mais da literatura do passado através de diferentes graus de intertextualidade, no entanto não poderá ser vista da forma original. $\mathrm{O}$ romance de Terron é justamente um modelo desse novo fazer literário, um livro que exige conhecimento da literatura por parte do seu leitor.

Em última instância, a obra de Terron fala-nos da finalidade da literatura, da impossibilidade de um mundo sem livros, e de como somente a própria literatura pode por fim a ela mesma. Em Não há nada lá a religião permitida e praticada é a literatura, "pela língua, pelos olhos e pelo livro, assim deve ser, prega a ordem máxima dos Sagrados Corações de Meremme, o livro nos vincula, o livro nos recorda de nossa humanidade, nos religa" (TERRON, 2011, p.65 - grifo do autor). Lembremo-nos aqui da etimologia da palavra religião, re- 
ligare, ligar de novo, somente o livro liga o autor ao leitor. Não parece ter ocorrido por acaso a escolha da passagem dos 7 (sete) selos, pelo autor, Deus só poderia estar segurando um livro. Por diversas passagens do Apocalipse trata-se do Livro da Vida, onde se encontra o nome das pessoas que serão salvas no juízo final, os livros são sagrados e é sobre isso que fala o romance de Terron.

\section{CONSIDERAÇÕES FINAIS}

Em 1941, em Mar do Prata, Jorge Luis Borges profetizava:

Talvez me enganem a velhice e o temor, mas tenho a suspeita de que a espécie humana - a única - está prestes a extinguir-se e que a Biblioteca perdurará: iluminada, solitária, infinita, perfeitamente imóvel, armada de volumes preciosos, inútil, incorruptível, secreta. (1999, p.42)

Para Borges o mundo é o livro, e o livro é o mundo. Para o autor nada é mais perfeito que o livro, e por consequência a própria literatura.

Joca Reiners Terron inverte um pouco a ideia de Borges, ele cria o fim do mundo, leia-se: o fim dos livros, sua personagem, o bispo de Macau, comenta: "somente a literatura pode terminar o que começou, não seria suficiente, o fim do livro e, em consequência, o fim do mundo, ao menos deste mundo, como conhecemos?" (TERRON, 2011, p.1, grifo do autor). Enquanto para Borges a humanidade se autodestruiria e apenas o que permaneceria seriam os livros, para Terron a literatura desencadearia o seu próprio fim, e como consequência o fim do mundo. Entretanto, para ambos o livro é o único objeto capaz de dar sentido para a existência. Beatriz Resende (2008) comenta, a respeito da obra literária de Terron: "[t] al apologia [ela se refere a um fragmento de uma obra do autor em 
que a literatura é sugerida como o único antídoto] da obra literária não se faz, porém, como expressão de qualquer utopia, de redenção pela arte, pelo sublime" (p.133). Terron tem uma visão pessimista da arte literária, embora seja visível a sua paixão pela literatura.

De acordo com Schollhammer (2011), “[o] romance de Terron é uma fantasia maldita da literatura, reescrita de sua genealogia viva e uma declaração de amor a essa face bem romântica, marcada por uma certa marginalidade, e a vocação de viver de sua arte e fazer dela uma vida" (p.133). A obra Não há nada lá é composta por personagens peculiares, os poetas malditos Baudelaire, Rimbaud, Fernando Pessoa, Aleister Crowley e os escritores bizarros tais como William Burroughs, Raymond Roussel e, se existiu, conforme Terron, Isidore Ducasse. Não deixando de ser bem exótica a profetisa católica Lúcia. Na metaliteratura produzida no romance de Terron, alinham-se matizes do decadentismo, do simbolismo, do surrealismo e do fantástico, porém com a singularidade humorística e paródica dos autores contemporâneos.

Conforme vimos até aqui, a literatura contemporânea, ou pósmoderna, se afastou do realismo formal, perdeu-se a preocupação de representar o mundo nas obras ficcionais. Nesse paradigma, muitos autores optam por criar um texto ficcional que reflita uma literatura voltada para si mesma, autoconsciente e autorreflexiva. Joca Reiners Terron escolhe esse caminho, a preocupação com a criação literária e a sua recepção torna-se mais relevante que a transposição mimética da realidade. Em última instância, a opção pela metaliteratura, obrigatoriamente perpassada pela intertextualidade, feita pelo autor evidencia seu profundo gosto e entendimento da arte literária. 


\section{REFERÊNCIAS}

BIBLIA. Novo testamento: Apocalipse. Versão online. In https://www.bibliaonline. com.br/acf/ap/5. Acesso em 12.Mai.2018.

BORGES, Jorge Luis (1999). "Biblioteca de Babel". In: . Obras Completas de Jorge Luis Borges. v I. São Paulo: Globo. p.38-42.In http://site.ufvjm.edu.br/ cafeliterario/a-biblioteca-de-babel-jorge-luis-borges/. Acesso em 12.Mai.2018. GASS, William (1974). A ficção e as imagens da vida. São Paulo: Cultrix. GOMES, Hélder. Metaliteratura (2010). In: CEIA, Carlos. E-Dicionário de termos literários de Carlos Ceia. In http://edtl.fcsh.unl.pt/encyclopedia/metaliteratura/ Acesso em 12.Mai.2018.

HALL, Stuart (2010). A identidade cultural da pós-modernidade. Belo Horizonte: UFMG. HUTCHEON, Linda (1988). A poetics of postmodernism: history, theory, fiction. Londres: Routledge.

(1980). Narcissistic narrative: the metafictional paradox. Ontario: Wilfrid Laurier University Press.

KRISTEVA, Júlia (1969). Introdução à Seminálise. São Paulo: Debates.

PERRONE-MOISÉS, Leyla (2011). O longo adeus à literatura. São Paulo: Folha de São Paulo, 10.Jul. In http://www1.folha.uol.com.br/ilustrissima/941210-olongo-adeus-a-literatura.shtml. Acesso em 18.Mai.2018.

RESENDE, Beatriz (2008). Contemporâneos: expressões da literatura brasileira no século XXI. Rio de Janeiro: Casa das Palavras: Bibliteca Nacional.

SARTRE, Jean-Paul (1968). Situações I. Lisboa: Publicaações Europa-América.

SCHOLLHAMMER, Karl Erik (2011). Ficção brasileira contemporânea. Rio de Janeiro: Civilização Brasileira.

TERRON, Joca Reiners (2011). Não há nada lá. São Paulo: Companhia das Letras. TEZZA, Cristovão (2002). O terceiro segredo de Fátima: Não há nada lá, de Joca Reiners Terron. In Revista Cult, 54. In http://www.cristovaotezza.com.br/textos/ resenhas/p_0201_cult.htm Acesso em 16.Mai.2018.

TODOROV, Tzevetan (2006). Introdução à literatura fantástica. São Paulo: Perspectiva.

WATT, Ian (1990). A ascensão do romance. São Paulo: Companhia das Letras. 